\title{
General vs. Regional Anesthesia and Neonatal Data (GRAND). A Retrospective Propensity Score Matched Study.
}

\author{
Liviu Cojocaru ${ }^{1}$, Cristiana Salvatori ${ }^{1}$, Sharon Amir ${ }^{1}$, Hyunuk Seung ${ }^{2}$, Katherine Nyman ${ }^{1}$, \\ Bhavani Kodali $^{1}$, and Ozhan Turan ${ }^{1}$ \\ ${ }^{1}$ University of Maryland School of Medicine \\ ${ }^{2}$ University of Maryland School of Pharmacy
}

June 1, 2021

\begin{abstract}
Objective To evaluate whether there is a difference in immediate neonatal outcomes with general anesthesia (GA) vs. regional anesthesia (RA) when induction of anesthesia to delivery time (IADT) is prolonged ([?]10 minutes). Methods This is a retrospective case-control study that included cases from July 2014 until August 2020. We reviewed all singleton pregnancies delivered between 24 and 42 weeks of gestation with IADT [?] 10 minutes. The propensity score (PS) matching method was performed using baseline characteristics. Analyses were performed with SAS software version 9.4. Results During the study period, we identified 258 cases meeting inclusion criteria. After the PS matching was applied, the study sample was reduced to 60 cases in each group. The median IADT was similar between groups [41.5m (30.5,52) vs. 46m (38-53.5), p=0.2]. There was no significant difference between groups with respect to arterial cord $\mathrm{pH}[7.24(7.21,7.26)$ vs. 7.23 (7.2,7.27), p=0.7]. Nor were there any associations between maternal characteristics and Apgar score at 5 minutes except Apgar score at 1 minute $(\mathrm{p}<0.001)$. No significant difference was identified in the rate of admission to the neonatal intensive care unit (NICU) [11 (52.4) vs. 10 (47.60], $\mathrm{p}=0.8$ ] or NICU length of stay between GA vs. RA [4(3-14) vs. 4.5(3-11), p=0.9]. Conclusion Our data indicate that with prolonged IADT, favorable neonatal outcomes are seen with both GA and RA, in contrast with previous studies performed decades ago. This underscores the need for re-appraisal of historic outcomes reflecting new modalities, techniques, and advances in the medical field.
\end{abstract}

\section{Hosted file}

GRAND.docx available at https://authorea.com/users/406404/articles/524474-general-vsregional-anesthesia-and-neonatal-data-grand-a-retrospective-propensity-score-matchedstudy

\section{Hosted file}

Tables.docx available at https://authorea.com/users/406404/articles/524474-general-vsregional-anesthesia-and-neonatal-data-grand-a-retrospective-propensity-score-matchedstudy 